\title{
Una nueva estrategia terapéutica en el cáncer de mama: quimioterapia metronómica
}

Khosravi Shahi P, Pérez Manga G. Una nueva estrategia terapéutica en el cáncer de mama: quimioterapia metronómica. An Med Interna (Madrid) 2007; 24: 261-262.

El cáncer de mama infiltrante (CMI) es la neoplasia más frecuente en la mujer en los países industrializados. En las últimas décadas ha habido una disminución de la mortalidad asociada al cáncer de mama (1), debido a las mejoras en su diagnóstico y tratamiento. Más del $90 \%$ de los cánceres de mama son esporádicos, y tan sólo el 10-15\% son de carácter hereditario o familiar (generalmente asociado a mutaciones de los genes BRCA 1 y 2, y TP53) (2).

El tratamiento del CMI es complejo y de carácter multidisciplinar, y debe incluir una óptima combinación de la cirugía, quimioterapia, radioterapia, hormonoterapia e/o inmunoterapia.

Una nueva variante en la administración de la quimioterapia denominada "metronómica", que consiste en la administración de dosis bajas de citostáticos, de forma continuada, ha demostrado su eficacia en la inhibición de la angiogénesis tumoral en el CMI. Diferentes fármacos citostáticos administrados de esta manera han demostrado su actividad antiangiogénica en el tratamiento de CMI, entre los que destacan la ciclofosfamida y el metotrexate por vía oral (3).

El estudio llevado a cabo por Colleoni M et al (4), que incluía a 63 pacientes con cáncer de mama metastático (CMM) politratado, demostró que el empleo de la quimioterapia metronómica $(\mathrm{QM})$ con dosis bajas de metotrexate $(2,5$ mg dos veces al día en el día $1^{\circ}$ y $2^{\circ}$ de cada semana) y ciclofosfamida ( $50 \mathrm{mg} /$ día) durante 6 meses de forma continua por vía oral era poco tóxica y eficaz. En este estudio se obtuvo una tasa de respuestas objetivas de 19\% (Intervalo de confianza al 95\% [IC95\%]: 10,2-30,9\%), y una tasa de beneficio clínico (TBC) de 31,7\% (IC95\%: 20,6-44,7\%). Además la administración de la QM en estas pacientes se asociaba con una disminución de los niveles séricos del factor de crecimiento del endotelio vascular (VEGF), el cual posee un papel clave en el proceso de la angiogénesis tumoral (5). Otros estudios han demostrado beneficios similares de la QM mediante el uso de dosis bajas de ciclofosfamida en el cáncer mama metastático (6).

La eficacia de la QM también se ha podido demostrar en la adyuvancia de CMI localizado, tal como lo demuestra el estudio fase II llevado a cabo por Bottini A et al (7). Este estudio incluía 114 mujeres ancianas con CMI localizado con recepto- res hormonales positivos que fueron randomizados a recibir letrozol (2,5 mg/día durante 6 meses) o una combinación de letrozol con ciclosfofamida (50 mg/día durante 6 meses). La tasa de respuesta global fue de $87,7 \%$ en la rama de QM frente al $71,9 \%$ del letrozol. Hubo una reducción significativamente mayor de la expresión de VEGF y Ki-67 en la pieza quirúrgica en la rama de la $\mathrm{QM}(\mathrm{p}=0,002$ y $\mathrm{p}=0,03$ respectivamente).

El subtipo de CMI HER-2 positivo presenta un peor pronóstico, puesto que se asocia con una sobreexpresión de genes relacionados con una mayor agresividad biológica. Además presenta una resistencia relativa a determinados agentes quimioterápicos y al tamoxifeno (8). Sin embargo, su historia natural ha cambiado con la introducción de la inmunoterapia mediante el empleo del anticuerpo monoclonal anti-HER-2, denominado trastuzumab (9). El estudio realizado por Orlando L et al. (10), evaluó la eficacia de la combinación de trastuzumab con una QM basada en ciclofosfamida y metotrexate en pacientes con CMM HER-2 positivo. Este estudio incluyó 22 pacientes previamente tratadas con otros agentes quimioterápicos y/o trastuzumab, obteniendo una tasa de remisión parcial de $18 \%$, y una TBC de $46 \%$. La mediana de tiempo a la progresión fue de 6 meses y la mediana de la duración de respuesta de 5 meses. De nuevo la toxicidad del tratamiento metronómico fue escasa. Además los resultados vertidos por este estudio, aunque precisa de una confirmación en estudios más amplios, sugieren que este tipo de administración de la quimioterapia podría obviar o retrasar la resistencia adquirida a trastuzumab, ya que la TBC en pacientes que habían progresado previamente al trastuzumab fue de $27 \%$.

La QM está siendo evaluado también en otros tipos de tumores malignos como el cáncer epitelial de ovario, melanoma avanzado refractario, cáncer de próstata metastático refractario, y cáncer de pulmón no microcítico avanzado.

\section{P. KHOSRAVI SHAHI, G. PÉREZ MANGA}

Servicio de Oncología Médica. Hospital General Universitario Gregorio Marañón. Madrid 


\section{Bibliografía}

1. Jemal A, Tiwani RC, Murray T, et al. Cancer statistics, 2004. CA Cancer J Clin 2004; 54: 8-29.

2. Ford D, Easton DF, Stratton M.Genetic heterogeneity and penetrance analysis of the BRCA1 and BRCA2 genes in breast cancer families. The breast cancer linkage consortium. Am J Hum Genet 1998; 62: 676-81.

3. Orlando L, Cardillo A, Rocca A, et al. Prolonged benefit with metronomic chemotherapy in patients with metastatic breast cancer. Anticancer Drug 2006; 17: 961-7.

4. Colleoni M, Rocca A, Sandri MT, et al. Low dose oral methotrexate and cyclophosphamide in metastatic breast cancer: antitumor activity and correlation with vascular endothelial growth factor leves. Ann Oncol 2002; 13: 73-80

5. Khosravi P. Angiogénesis y neoplasias. An Med Interna (Madrid) 2006; 23: 355-6.

6. Munoz R, Man S, Shaked Y, et al. Higly efficacious nontoxic preclini- cal treatment for advanced metastatic breast cancer using combination oral UFT-cyclophosphamide metronomic chemotherapy. Cancer Res 2006; 66: 3386-91

7. Bottini A, Generali D, Brizzi MP, et al. Randomized phase II trial of letrozol and letrozol plus low-dose metronomic oral cyclophosphamide as primary systemic treatment in elderly breast cancer patients. J Clin Oncol 2006; 24: 3623-8.

8. Burstein HJ. The distinctive nature of HER2 of breast cancers. N Engl J Med 353; 16: 1652-4.

9. Khosravi P, Pérez-Manga G. La relevancia clínica de la sobreexpresión de HER-2 en el cáncer de mama. An Med Interna (Madrid) 2006; 23 : 103-4.

10. Orlando L, Cardillo A, Ghisini R, et al. Trastuzumab in combination with metronomic cyclophosphamide and methotrexate in patioents with Her-2 positive metastatic breast cancer. BMC Cancer 2006; 6: 225-33. 